\title{
ANALISIS PERAN SEKRETARIAT DEWAN (SETWAN) DPRD KOTA SUNGAI PENUH BERDASARKAN UNDANG-UNDANG KETERBUKAAN INFORMASI PUBLIK
}

\author{
BADRIZAL \\ STIA Nusantara Sakti Sungai Penuh \\ email: \\ badrizal@gmail.com
}

\begin{abstract}
In preliminary obsevations, the researcher was interested in knowing how and to what extent the role of the Sungai Penuh government, especially the secretariat of the Sungai Penuh DPRD council, in implementing law number 14 of 2008, regarding publik information disclosure. The approach used in this research is qualitative. Data collection techniques and tools in this study were interviews, observatioan and documentation. Data collection tools in the form of questionnaires, pen, books/paper, recording devices. The unit of analysis is individual officers and staff at the DPRD Secretariat of Sungai Penuh city. Here the researcher wants to know the extent of the role of the Secretariat of the Council in providing information services to the public, whether it is running well or not. Where Law number 14 of 2008, demands and obliges state administrators to give the public the right to obtain information on every activity organized by the organizer or a state institution. To get the title of best servant, of course, state officials must carry out activities in accordance with the applicable rules and regulations.

Keyword: professionalism in handling information services towards transparency in implementing clean government.
\end{abstract}

\begin{abstract}
ABSTRAK
Pada observasi awal peneliti tertarik ingin mengetahui bagaimana dan sejauhmana peran pemerintah kota Sungai penuh, khususnya Sekretariat Dewan DPRD kota Sungai Penuh, dalam mengimplementasikan Undang-undang nomor 14 tahun 2008, tentang Keterbukaan Informasi Publik. Adapun pendekatan yang digunakan dalam penelitian ini adalah kualitatif. Teknik dan alat pengumpulan data dalam penelitian ini adalah wawancara, observasi dan dokumentasi. Alat pengumpulan data berupa daftar pertanyaan, pena, buku/kertas, alat perekam. Unit analisisnya adalah individu Penjabat dan staf di Sekretariat DPRD kota Sungai Penuh. Disini peneliti ingin mengetahui sejauhmana peran Sekretariat Dewan terhadap pelayanan informasi yang dilakukan terhadap masyarakat, apakah sudah berjalan dengai baik atau tidak. Dimana Undang-undang nomor 14 tahun 2008, menuntut dan mewajibkan penyelenggara negera memberikan hak masyarakat mendapatkan informasi setiap kegiatan yang diselenggarakan oleh penyelenggara atau sebuah institusi negera. Untuk mendapat predikat pelayan terbaik, tentunya penyelenggara negara harus melaksanakan kegiatan sesuai dengan aturan dan ketentuan yang berlaku.
\end{abstract}

Kata Kunci: Profesionalitas Penanganan Pelayanan Informasi Menuju Transparansi Pelaksanaan Pemerintahan yang bersih 


\section{PENDAHULUAN}

Diera globalisasi, ilmu pengetahuan dan teknologi informasi mengalami perkembangan yang pesat. Mengingat pentingnya peran sekretariat dewan (setwan) DPRD kota Sungai Penuh, terhadap penyampaian informasi bagi masyarakat (publik), maka diperlukan adanya prosedur pengelolaan informasi yang tepat sesuai dengan Undang-undang nomor 14 tahun 2008, tentang informasi publik.

Keberhasilan manajemen di Sekretariat DPRD Kota Sungai Penuh dalam pengelolaan dan penyampaian informasi yang efektif sangat dipengaruhi oleh sarana dan prasarana yang digunakan dan faktor sumber daya manusianya itu sendiri. Keterbatasan sumber daya manusia biasanya akan membawa dampak, saat informasi itu akan disampaikan.

Dalam pengelolaan informasi publik pada Sekretariat DPRD Kota Sungai Penuh masih ada kegiatan yang belum dilaksanakan secara optimal. Hal ini tercermin dalam kegiatan penataan dan klasifikasi informasi. Selain itu, belum adanya petugas khusus pengelolaan infomasi yang akan disampaikan kepada publik. Petugas penyampai informasi masih berinduk pada humas setda kota Sungai Penuh, sementara sekretariat DPRD kota Sungai Penuh bersifat membantu.

Informasi merupakan salah satu hal yang penting di dalam suatu instansi, perusahaan, organisasi, lembaga serta lingkungan yang berada di luar sistem. Informasi dianggap sangat penting karena dengan adanya informasi, wawasan dapat semakin bertambah, dapat mengetahui keadaan atau situasi di lingkungan sekitar, dapat mengurangi ketidak pastian dan resiko kegagalan, serta dapat membantu dalam mengambil suatu kesimpulan dan keputusan yang efektif dan efisien. Informasi yang baik dan berkualitas adalah informasi yang relevan, yang diberikan sesuai dengan kebutuhannya, baik pada kelengkapan materinya, waktu pemberian informasinya dalam hal ini ialah ketepatan waktunya, keakuratan datanya, dan sebagainya. Informasi yang baik dan berkualitas adalah informasi yang relevan, yang diberikan sesuai dengan kebutuhannya, baik pada kelengkapan materinya, waktu pemberian informasinya dalam hal ini ialah ketepatan waktunya, keakuratan datanya, dan sebagainya.

Akurat dalam arti tidak bias, yakni informasi yang kita peroleh sesuai dengan permasalahan yang sedang dihadapi dan berasal dari sumber yang dapat dipercaya. Tepat waktu dalam artian informasi diterima pada saat dibutuhkan. Relevan, hanya informasi yang berhubungan erat dengan permasalahan yang kita hadapi atau informasi yang akan digunakan. Lengkap dalam artian bahwa informasi diperoleh dari berbagai sumber secara lengkap. Agar informasi dapat dilakukan secara cepat dan akurat, maka saat ini, tak ada pilihan lain selain memanfaatkan teknologi komputer.

Dalam pengamatan peneliti, masih terdapat beberapa indikasi yang dapat menunjukkan belum maksimalnya peranan Sekretariat DPRD Kota Sungai Penuh dalam mendukung dan menganalisa undang-undang keterbukaan informasi publik. Berdasarkan uraian diatas, maka Penelitian penulis mengambil judul "Analisis Peran Sekretariat Dewan (Setwan) DPRD Kota Sungai Penuh Berdasarkan Undang-undang Keterbukaan Informasi Publik".

\section{METODE PENELITIAN}

\section{Jenis Penelitian}

Pendekatan yang digunakan dalam penelitian ini adalah pendekatan kualitatif. Pendekatan kualitatif adalah suatu prosedur penelitian yang menghasilkan data deskriptif berupa kata-kata tertulis atau lisan orang-orang dan perilaku yang dapat diamati. Pendekatan kualitatif memiliki karakteristik alami (Natural serfing) sebagai sumber data langsung, deskriptif, proses lebih dipentingkan dari pada hasil. Analisis dalam penelitian kualitatif cenderung dilakukan secara analisis induktif, dan maknamakna merupakan hal yang esensial. (Lexy Moleong, 2006:04). 
Objek dalam penelitian kualitatif adalah objek yang alamiah, atau natural setting, sehingga penelitian ini sering disebut penelitian naturalistic. Obyek yang alami adalah objek yang apa adanya, tidak dimanipulasi oleh peneliti sehingga kondisi pada saat peneliti memasuki objek, setelah berada di objek dan keluar dari objek relatif tidak berubah. Dalam penelitian kualitatif peneliti menjadi instrumen. Oleh karena itu, dalam penelitian kualitatif instrumennya adalah orang atau Human instrument. Untuk menjadi instrumen peneliti harus memiliki bekal teori dan wawasan yang luas, sehingga mampu bertanya, menganalisis, memotret dan mengkontruksi objek yang diteliti menjadi jelas dan bermakna. Kriteria data dalam penelitian kualitatif adalah data yang pasti. Data yang pasti adalah data yang sebenarnya terjadi sebagaimana adanya, bukan data yang sekedar terlihat, terucap, tetapi data yang mengandung makna dibalik yang terlihat dan terucap tersebut (Sugiyono,2008:

\section{Informan Penelitian}

Informan dalam penelitian kualitatif yaitu informan penelitian yang memahami informasi tentang objek penelitian. Informan yang dipilih harus memiliki kriteria agar informasi yang didapatkan bermanfaat untuk penelitian yang dilakukan. Terdapat kriteria - kriteria untuk menentukan informan penelitian yang dikatakan oleh para ahli.

Lokasi penelitian ini di Sekretariat Kantor DPRD kota Sungai Penuh. Sehingga penulis menentukan informan penelitian dalam penelitian ini berjumlah Lima belas orang, yang terbagi menjadi tiga belas orang sebagai informan formal atau informan kunci dan dua orang sebagai informan informal.

Tokoh formal yang menjadi subjek atau informan dalam penelitian ini yaitu :

1. Sekretaris Dewan DPRD kota Sungai Penuh, peneliti memilih Sekretaris Dewan DPRD kota Sungai Penuh karena memiliki wewenang dalam menyetujui setiap keputusan di dalam kantor tersebut.

2. Kepala Bagian, Kepala Bidang dan Sub Bagian yang terlibat langsung dalam memberikan informasi yang berhubungan dengan pelayanan informasi publik.

Sedangkan tokoh informal yang menjadi informan dalam penelitian ini yaitu dua orang staf honorer di sekretariat DPRD kota Sungai Penuh. Peneliti menambahkan subjek atau informan sekunder ini karena peneliti bisa mendapatkan informasi yang berhubungan dengan kegiatan pelayanan informasi publik yang dilakukan di kantor DPRD kota Sungai Penuh.

\section{Teknik Pengumpulan Data}

Teknik pengumpulan data yang digunakan dalam penelitian ini adalah wawancara mendalam (Indepth Interview) yaitu teknik mengumpulkan data yang dilakukan dengan mengadakan tanya jawab langsung kepada subjek atau informan penelitian. Peneliti dalam hal ini mempersiapkan daftar pertanyaan yang relevan dengan tujuan penelitian sejauhmana peran sekretariat dewan menganaisis undang-undang nomor 14 tahun 2008 tentang keterbukaan informasi publik. Dalam proses wawancara, peneliti merekam atau dan mencatat hasil jawaban yang diberikan oleh informan.

\section{Interpretasi Data}

Adapun teknik analisis data kualitatif dilakukan dengan tahap sebagai berikut :

1. informasi Pengumpulan melalui wawancara, observasi langsung dan dokumentasi

2. Reduksi Data

Reduksi data yaitu proses pemilihan, pemusatan perhatian dan penyederhanaan, pengabstrakkan dan transformasi data kasar yang muncul dari catatan - catatan tertulis di lapangan. Di mana setelah penulis memperoleh data, harus lebih dulu dikaji kelayakannya dengan memilih data mana yang benar - benar dibutuhkan dalam penelitian ini.

3. Penyajian Data

Penyajian data dibatasi sebagai sekumpulan informasi tersusun yang disesuaikan dan diklarifikasi untuk mempermudah peneliti dalam menguasai data dan tidak terbenam dalam setumpuk data.

4. Verifikasi (Menarik Kesimpulan) 
Penarikan kesimpulan dilakukan dengan cermat dengan melakukan berupa tinjauan ulang pada catatan - catatan lapangan sehingga data-data yang verifikasi ada telah diuji validitasnya. Sehingga diperoleh kesimpulan yang jelas kebenaran dan kegunaannya

\section{HASIL DAN PEMBAHASAN}

Proses pemberian pelayanan informasi publik yang profesional yang sesuai dengan tuntutan Undang-undang nomor 14 tahun 2008 tentang keterbukaan informasi publik pada dasarnya harus dilakukan sesuai dengan prinsip-prinsip atau ketentuan-ketentuan administrasi organisasi yang benar dan telah ditetapkan. Profesionalisme merupakan tingkah laku, keahlian atau kualitas dan seseorang yang professional. Profesionalisme dapat dituang dalam kerangka pemikiran berikut:

\section{Gambar Kerangka Pemikiran}

Faktor yang mempengaruhi :

- Kepemimpinan

- Kedisiplinan

- Kualitas SDM

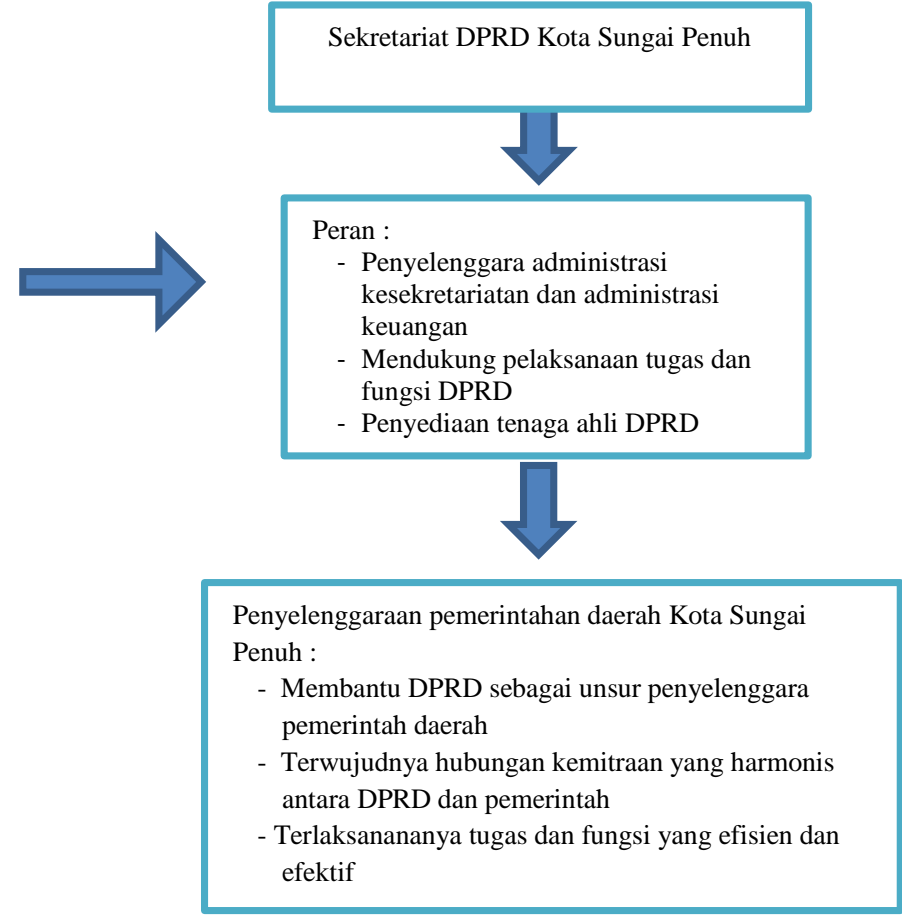

\section{KESIMPULAN}

Berdasarkan uraian hasil pembahasan diatas maka dapat ditarik kesimpulan dalam penelitian pada skripsi ini adalah sebagai berikut:

1. Bahwa Undang-undang Nomor 14 Tahun 2008 tentang Keterbukaan Informasi Publik di lingkungan DPRD Kota Sungai Penuh belum dianalisis secara maksimal.

2. Belum tersedianya secara lengkap dan akurat tentang informasi yang wajib diumumkan secara berkala dan setiap saat kepada publik, meskipun telah tersedia berbagai bentuk media akses Informasi Publik.

3. Dalam penelitian ini, penulis juga menemukan adanya Faktor Pendukung, diantaranya ada media akses keterbukaan informasi publik, dan aturan mengenai prosedur layanan 
informasi publik sebagaimana yang tercantum pada Peraturan Walikota Nomor 7 Tahun 2016.

4. Peneliti juga menemukan adanya faktor penghambat, seperti Humas Sekretariat DPRD Kota Sungai Penuh hanya PPID (Pejabat Pengelola Informasi dan Dokumentasi) bersifat Pembantu, sedangkan PPID induk adalah Humas Sekretariat Daerah Kota Sungai Penuh, belum tersedianya sarana dan prasarana penunjang layanan informasi publik, serta belum ada klasifikasi secara jelas mengenai jenis-jenis informasi publik.

\section{UCAPAN TERIMA KASIH}

Diucapkan terima kasih kepada semua pihak yang telah berkontribusi dalam penulisan jurnal ini, sehingga jurnal ini dapat diselesaikan dengan baik. Dan juga terima kasih kepada penglola jurnal Qawwam, sehingga bisa dipublikasan di OJS Qawwam.

\section{DAFTAR PUSTAKA}

Anggoro, M. Linggar. 2002 Teori Dan Profesi kehumasan, serta aplikasinya di Indonesia, Jakarta. Bumi Aksara.

Bungin, Burhan. 2013. Metodologi Penelitian Sosial dan Ekonomi Format-format kuantitatif dan kualitatif untuk studi sosiologi, kebijakan publik, komunikasi, manajemen, dan pemasaran. Jakarta: Kencana

Effendy, Onong Uchjana. 1989. Human Relations dan Public Relations dalam Manajemen. Bandung: CV Mandar Maju

Pebi Julianto. 2018. Pengaruh Pengetahuan dan Keterampilan Terhadap Prestasi Kerja Pegawai Pada Mtsn Model Sungai Penuh. E Jurnal Administrasi Nusantara. Sungai Penuh. Effendy, Onong Uchjana. 2009. Human Relation \& Public Relation. Bandung: CV Mandar Maju.

Effendy, Onong Uchjana. 2011. Ilmu Komunikasi Teori dan Praktek Cetakan ke23.Bandung: PT Remaja Rosdakarya

F. Rachmadi. 1992. Public Relation dalam Teori dan Praktek. Jakarta: PT GramediaPustaka Utama.

Fuad, Afdhal Ahmad. 2004. Tips dan trik Public Relation. Jakarta. PT.Grasindo.

Ruslan, Rosady. 2005. Manajemen Public Relations dan Media Komunikasi. Jakarta: PT Raja Grafindo Persada

Pebi Julianto. 2018. Pengaruh Sistem Kearsipan Terhadap Efisiensi Kerja Pada koantor Camat Air Hangat Kabupaten Kerinci. E Jurnal Administrasi Nusantara. Sungai Penuh.

Ruslan, Rosady. 2006. Manajemen Public Relation \& Media Komunikasi Konsepsidan Aplikasi. Jakarta: PT Raja Grafindo Persada. 
Ruslan, Rosady. 2012. Manajemen Public Relations dan Media Komunikasi. Jakarta: PT Raja Grafindo Persada

Pebi Julianto. 2019. Pengaruh Disiplin Kerja Terhadap Prestasi Kerja Pegawai pada Puskesmas di kecamatan Depati VII Kabupaten Kerinci. E Jurnal Administrasi Nusantara. Sungai Penuh.

Paul H. Dauglas, Wahyudi Kumorotomo 1992. Ketentuan Transparansi dalam Pelayanan Publik.

Scott M.Cutliip and Allen Center. 2001. Public Relation. Jakarta. PT. Remaja Rosdakarya

David Welkinson (0806322514). Peran humas pada lembaga Dewan Perwakilan Rakyat (DPR) RI dalam implementasi Undang-Undang Keterbukaan Informasi Publik (UU KIP) No.14 tahun 2008 (Internal Journal of communication).Depok : Universitas Indonesia.

Titis Hidayati (2014). Peran humas dalam implementasi Undang-Undang Keterbukaan Informasi Publik No.14 tahun 2008 di Badan Pemeriksan Keuangan (BPK) RI di Jakarta (Indonesian Jurnal of Communication). Yogyakarta : Universitas Gadjah Mada

Pebi Julianto. 2014. Evaluasi Pelaksanaan Program Satu milyar Satu kecamatan (Samisake) di kecamatan Depati Tujuh Kabupaten Kerinci Provinsi jambi tahun 2014. OSF Preprints. Jakarta.

Muhammad Adi Pribadi, Mahasiswa Jurusan Public Relations Departemen Komunikasi Pemasaran. Peranan Public Relations dalam Kegiatan Human Relations Perusahaan Terhadap Motivasi Kerja Karyawan PT Ciptalift Sejahtera (Jurnal). Jakarta : Universitas Binus ( Bina Nusantara).

Anang wibowo (100080077). Peranan Humas Pemda Sragen dalam menciptakan citra lembaga (Jurnal Ilmu Komunikasi Indonesia). Surakarta : Universitas Muhammadiyah. 